\title{
GOSPODARSKA VAŽNOST I RASPROSTRANJENOST BIJELE DJETELINE (TRIFOLIUM REPENS L.) NA PODRUČJU REPUBLIKE HRVATSKE
}

\author{
ECONOMIC VALUE AND DISTRIBUTION OF WHITE CLOVER \\ (TRIFOLIUM REPENS L.) IN CROATIA
}

\section{Dubravka Dujmović Purgar, Dubravka Koprivnjak, Snježana Bolarić}

\section{SAŽETAK}

Bijela djetelina porijeklom je iz područja Mediterana, a smatra se autohtonom vrstom za cijelu Europu. Proširila se zahvaljujući kolonizatorima po cijelom svijetu. U skladu s klimatskim i reljefnim različitostima Hrvatske ova vrsta se prilagodila različitim uvjetima zbog čega su se razvili različiti ekotipovi. Bijela djetelina ima pozitivan utjecaj na plodnost tla, te je jedan od najboljih fiksatora dušika. Iznimne je krmne vrijednosti, te se koristi u smjesi s travama za hranidbu stoke, pogotovo muznih krava. Vrlo je medonosna, ali i ljekovita vrsta.

Ključne riječi: Trifolium spp., bijela djetelina, rasprostranjenost, prirodne populacije, genetska raznolikost, Hrvatska

\begin{abstract}
White clover is a native species in the Mediterranean area and it is a native species in the whole of Europe. It has spread, thanks to colonizers, all over the world. In accordance with the climatic and relief differences of Croatia, this species has adapted to and developed different ecotypes. White clover has a positive effect on soil fertility, as well as the best nitrogen fixation. It is of exceptional fodder value. For that reason, it is used as mixture with grasses in livestock feeding, especially dairy cows. It is a very melliferous plant, as well as medicinal.
\end{abstract}

Key words: Trifolium spp., white clover, distribution, natural populations, genetic variability, Croatia 
Dubravka Dujmović Purgar i sur.: Gospodarska važnost i rasprostranjenost bijele djeteline (Trifolium repens L.) na području Republike Hrvatske

Bijela djetelina - porijeklo, morfologija, ekologija

Pretpostavlja se da je bijela djetelina porijeklom iz područja Mediterana (Hirano 2005.) u koje spada i područje Republike Hrvatske. Smatra se autohtonom vrstom za cijelu Europu i centralnu Aziju, zapadni dio Bajkala kao i područja sjeverne Afrike (Maroko, Tunis). Iz svog centra nastanka proširila se zahvaljujući kolonizatorima po cijelom svijetu i sada je rasprostranjena osim u Europi i u Aziji, sjevernoj Africi, Sjevernoj i Južnoj Americi, te Australiji. Naturalizirana je u Kini, Mongoliji, Koreji i Japanu (Hirano 2005.).

Od samog početka ova vrsta zauzela je značajno mjesto u životu ljudi, prvenstveno zbog velike krmne vrijednosti preko medonosnosti do ljekovitosti, pa čak i kao religijski element.

U svijetu se smatra da je bijela djetelina najvažnija pašnjačka leguminoza roda Trifolium, a rod Trifolium u svijetu obuhvaća 250 jednogodišnjih ili višegodišnjih vrsta djetelina (Evans 1976.). U Europi je zabilježeno 99 vrsta djetelina (Coombe 1968.). Oko 25 vrsta djetelina koristi se u ishrani životinja, a 10 vrsta ima agronomsku važnost (Evans 1976.). Prema podacima Flora Croatica Database u Hrvatskoj postoji 77 vrsta i podvrsta djetelina.

Bijela djetelina pripada porodici mahunarki (fam. Fabaceae). To je višegodišnja zeljasta biljka puzave razgranjene stabljike u obliku vriježa pomoću kojih formira jastučiće različite veličine. Stabljika ima sposobnost zakorjenjivanja na koljencima, te joj je na taj način osigurano i vegetativno razmnožavanje. Korijenov sustav je plitak i razvija se u površinskom dijelu tla, a samo glavni korijen prodire nešto dublje. Zato na bijelu djetelinu može nepovoljno djelovati utjecaj suše $\mathrm{i}$ visokih temperatura, kada zaostane $u$ vegetaciji.

Listovi se nalaze na dugim peteljkama (do $20 \mathrm{~cm}$ ), a sastoje se od 3 obrnuto jajolike liske s bijelim trokutastim mrljama. Cvjetovi su dvospolni, pentamerni, čaška je zvonasta, a vjenčić je nalik na leptira (tipične građe mahunarki) bijele ili rijetko ružičaste boje. Cvjetovi su skupljeni u glavice koje sadrže 40 do 80 cvjetova. Cvatove bijele djeteline oprašuju pčele, bumbari i leptiri. Cvate od svibnja do kasne jeseni. Kad ocvatu, cvatovi posmeđe i priklanjaju se tlu. Plod je linearna, spljoštena mahuna koja sadrži 3 do 4 svjetlosmeđe sjemenke (Šoštarić - Pisačić \& Kovačević 1968., Čižek 1970., Frame i sur. 1998., Dubravec \& Dubravec 2001.). 
Dubravka Dujmović Purgar i sur.: Gospodarska važnost i rasprostranjenost bijele djeteline (Trifolium repens L.) na području Republike Hrvatske

Bijela djetelina je stranooplodna vrsta te je prisutna velika genetska varijabilnost $u$ većini morfoloških svojstava poput boje cvijeta i izgleda listova (Uher 2002.), a svaka biljka je genetički jedinstvena (Frame i sur. 1998.). Bijela djetelina je prirodni tetraploid s 32 kromosoma, iako se ponaša kao diploid (Frame i sur. 1998.). Ova vrsta oplemenjuje se još od 1930. godine i u svijetu postoji preko 300 kultivara.

Zahvaljujući svojoj velikoj adaptabilnoj sposobnosti bijela djetelina je prilagođena na različite klimatske uvjete od Arktika do subtropskih uvjeta kao i različitim nadmorskim visinama (Hirano 2005.). Bijela djetelina je prisutna od poplavnih do suhih staništa, a pogoduju joj godine s vlažnijim ljetom. Preferira ocjedite površine, a pojavljuje se i u voćnjacima, uz putove, uz nasipe i sl. Teško podnosi zasjenu stoga ne raste na površinama koje se slabo održavaju. Bijela djetelina traži teža, zbijena tla, iako uspijeva i na lakšima, ali i na veoma vlažnim i močvarnim tlima (Šoštarić Pisačić 1967.).

Bijela djetelina - uporabna vrijednost

Bijela djetelina ima vrlo pozitivan utjecaj na plodnost tla, jer ostavlja veliku količinu korijenja u mekoti pa povoljno djeluje na stvaranje „stabilne“ mrvičaste strukture, te povećanje poroznosti i kapaciteta za vodu (Šsostarić Pisačić 1967.). Kada svemu tome pridodamo i postojanje kvržičnih bakterija bijela djetelina izvrstan je meliorator tla. Stoga sjetva djetelina može rezultirati značajnim financijskim uštedama za poljoprivrednike (Hirano 2005.).

Bijela djetelina je jedan od najboljih fiksatora dušika $(100 \mathrm{~kg} / \mathrm{ha})$, iako razvoj kvržičnih bakterija ovisi o kiselosti tla. Za normalan razvoj kvržičnih bakterija i odvijanje procesa fiksacije dušika poželjan pH je iznad 5.0 (Frame i sur. 1998.). Učinkovitija fiksacija atmosferskog dušika može se postići cijepljenjem sjemena bakterijama roda Rhizobium kod sjetve (Uher 2002.).

Različite uporabne vrijednosti bijele djeteline istražuju se intenzivnije posljednja dva desetljeća, a godišnje se sije 8000 - 10000 tona sjemena (Frame i sur. 1998.).

Zahvaljujući puzajućoj stabljici nadzemna masa bijele djeteline sastoji se od lišća, cvjetova i peteljki. Zbog toga ima manji sadržaj sirovih vlakana i balasta od drugih djetelina (Šoštarić - Pisačić 1967.). Hranjiva vrijednost 
Dubravka Dujmović Purgar i sur.: Gospodarska važnost i rasprostranjenost bijele djeteline (Trifolium repens L.) na području Republike Hrvatske

bijele djeteline je vrlo visoka jer u vegetativnom stadiju sadrži $25-30 \%$ sirovog proteina, što je naročito pogodno za muzne krave kojima je potrebna krma bogata proteinima. Također, nije zanemariva i probavljivost organske tvari koja iznosi i preko $80 \%$. Prinos suhe tvari u prosjeku se kreće od 7,7 do 9,7 t/ha već u godini sjetve, odnosno 11,5 do 13,2 t/ha u prvoj godini korištenja (Uher 2005.). Zanimljivo je da bijela djetelina ne gubi na kvaliteti ni nakon cvatnje (Šoštarić - Pisačić 1967.).

Iskorištavanje bijele djeteline u svježem stanju dovodi do nadimanja stoke, pa se naročito iz tog razloga ova vrsta uzgaja u smjesi s travama (djetelinsko-travne smjese). Također bijela djetelina može sadržavati glikozid (lotaustralin) koji u slučaju enzimatske aktivnosti stvara otrovnu cijanovodičnu kiselinu (HCN) (Šoštarić Pisačić 1967., Čižek 1970.). Ova kombinacija može dovesti do trovanja stoke.

Bijela djetelina uzgaja se radi proizvodnje kvalitetnog sijena za ishranu domaćih životinja, prvenstveno za ishranu mliječnih krava u svrhu proizvodnje kvalitetnog mlijeka. Može se naći na pašnjacima, čak štoviše na intenzivnim pašnjacima češće je zastupljena u jakom udjelu kao jedina mahunarka. A što je intenzivniji režim ispaše, to više dominira bijela djetelina ispred ostalih mahunarki. Bijela djetelina je proširena i na prirodnim livadama, ali sa znatno manjim udjelom (Šoštarić - Pisačić \& Kovačević 1968.). Upravo lokalne populacije bijele djeteline predstavljaju potencijalan izvor svojstava kao što je tolerantnost na različite abiotske stresove koja se mogu koristiti u oplemenjivačkim programima. U skladu s klimatskim i reljefnim različitostima Hrvatske ova vrsta se prilagodila različitim uvjetima zbog čega su se razvili brojni ekotipovi. Naime, zahvaljujući svojoj velikoj sposobnosti adaptacije bijela djetelina može rasti na različitim tipovima tala i u različitim klimatskim uvjetima (Frame et al. 1998.).

Bijela djetelina se navodi kao medonosna biljka i predstavlja vrlo dobru pčelinju pašu (Šimić 1980., Tucak i sur. 1999., Dujmović Purgar \& Hulina 2007.). Bijelu djetelinu pčele posjećuju tijekom cijelog perioda cvatnje koji počinje u svibnju i traje do prvih mrazeva. Međutim, pčele ne mogu iskoristiti nektar prebujnih primjeraka bijele djeteline zbog preduboke čaške. Pčela treba za skupljanje jednog tereta peludi pohoditi 580 cvjetova bijele djeteline (Šimić 1980.). Med bijele djeteline veoma je finog okusa. 
Dubravka Dujmović Purgar i sur.: Gospodarska važnost i rasprostranjenost bijele djeteline (Trifolium repens L.) na području Republike Hrvatske

Bijela djetelina navodi se i kao ljekovita vrsta. Naime, u narodnoj medicini se upotrebljava protiv reume i gihta (Pahlow 1989.).

Bijela djetelina - rasprostranjenost u Hrvatskoj

Bijela djetelina je široko rasprostranjena vrsta i može se pronaći u svim regijama Republike Hrvatske. Zastupljena je od nizinske, preko gorske do sredozemnog dijela Hrvatske (Marković - Gospodarić 1965., Horvatić i sur. 1967.-68., Kovačević \& Šatović 1968., Hruška-Dell'Uomo 1976., RegulaBevilacqua 1979., Trinajstić 1980., Hećimović 1984., Marković 1984., Topić 1984., Trinajstić 1985., Marković 1987., Hulina 1991., Stančić 1994., Pandža 1998., Topić 1998., Vrbek 2000., Milović 2002., Dujmović Purgar 2006., Hulina 2007., Flora Croatica Database http://hirc.botanic.hr/fcd.aspx).

Višegodišnje istraživanje (2007.-2010.) provedeno je na livadama sjeverozapadne Hrvatske (Hrvatskog Zagorja, Žumberačko-Samoborsko gorje), Like i Gorskog kotara s ciljem prikupljanja podataka o nalazištima autohtonih populacija bijele djeteline u svrhu inventarizacije genetske raznolikosti djetelina, kao važnog genetskog izvora u oplemenjivanju bilja, te prikupljanja i očuvanja njene raznolikosti.

Vlastita istraživanja su nadopunjena literaturnim podacima o nalazištima bijele djeteline na području cijele Republike Hrvatske. U literaturi se navode podaci o rasprostranjenosti bijele djeteline (karta 1.) na području Dalmacije (sjeverna Dalmacija - Horvatić i sur. 1967.-68., Šipan - Hećimović 1984., Murter - Pandža 1998., Korčula - Trinajstić 1985., Šibenik - Milović 2002.), Gorskog kotara (Trinajstić 1980., Marković 1984., Velika Kapela - Hulina 2007.), središnje Hrvatske (Turopolje - Hulina 1991., Strahinčica - RegulaBevilaqua 1979., Moslavina - Hruška- Dell'Uomo 1976., Žumberak - Vrbek 2000., Plešivica - Dujmović Purgar 2006., područje Zagreba - MarkovićGospodarić 1965., Kovačević i Satović 1968., sjeverozapadna Hrvatska Marković 1987.), zapadna Slavonija (Podravina - Topić 1998.). Na taj način prikupljeni su podaci za izradu karte rasprostranjenosti bijele djeteline (karta 1. - Flora Croatica Database). 
Dubravka Dujmović Purgar i sur.: Gospodarska važnost i rasprostranjenost bijele djeteline (Trifolium repens L.) na području Republike Hrvatske

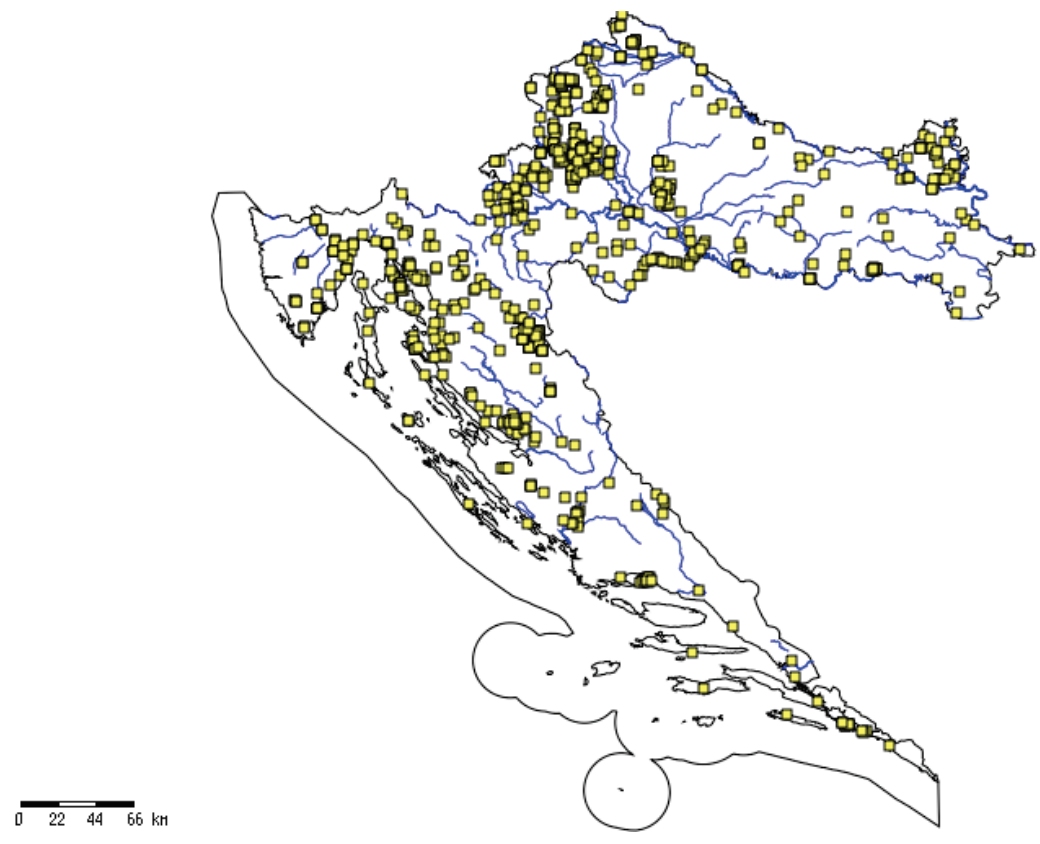

Karta 1. Rasprostranjenost bijele djeteline u Hrvatskoj (Flora Croatica Database, Nikolić, 2020.)

Fig. 1 The map of Croatia with highlighted habitats of white clover (literature data)

\section{ZAKLJUČAK}

Najkvalitetnija pašnjačka mahunarka koja je prirodno rasprostranjena $u$ Hrvatskoj je bijela djetelina. U Hrvatskoj postoji još 77 vrsta djetelina. U uzgoju se osim bijele najčešće nalazi i crvena djetelina. Obje vrste imaju široku amplitudu zahtjeva s obzirom na tlo, ali najbolje uspijevaju na srednje teškim i teškim tlima slabo kisele do neutralne reakcije. Ipak, bijela djetelina, za razliku od crvene djeteline, dobro uspijeva i na lakšim, kao i na zamočvarenim tlima. Bijela djetelina je zabilježena na području cijele Republike Hrvatske. Naime, ona je porijeklom iz područja Mediterana (mediteranski gencentar) u koji spada i područje Republike Hrvatske. 
Dubravka Dujmović Purgar i sur.: Gospodarska važnost i rasprostranjenost bijele djeteline (Trifolium repens L.) na području Republike Hrvatske

\section{LITERATURA}

1. Coombe D.E. (1968.): Trifolium In Tutin T.G. i sur. (eds.): Flora Europaea 2: 157-172, University Press, Cambridge.

2. Čižek, J. (1970.): Proizvodnja krmnog bilja. Sveučilište u Zagrebu.

3. Dubravec, K.D., Dubravec, I. (2001.): Biljne vrste livada i pašnjaka. Školska knjiga, Zagreb.

4. Dujmović Purgar, D. (2006.): Korovna flora Plešivičkog prigorja. Magistarski rad: 1- 114.

5. Dujmović Purgar, D., Hulina, N. (2007.): Medonosne biljne vrste Plešivičkog prigorja (SZ Hrvatska). Agronomski glasnik 1: 3-22.

6. Evans, A.M. (1976.): Clovers (Trifolium spp.) Leguminosae - Papilionate In: Simmonds, N.W. (ed.). Evaluation of Crop Plants. Longmans, London: 175-179.

7. Flora Croatica Database (http://hirc.botanic.hr/fcd.aspx)

8. Frame, J., Charlton, J.F.L., Laidlaw, A.S. (1998.): Temperate forage legumes. CAB International, Wallingford, UK.

9. Hećimović, M. (1984.): Grassland Vegetation of the Island of Šipan. 18. simpozij Istočnoalpsko-dinarskog društva za proučavanje vegetacije. Acta Bot. Croat. 43: 161-166.

10. Hirano R. (2005.): Ecogeographic and genetic survey of white clover (Trifolium repens L.) on St Kilda. MS thesis University of Birmingham, U.K.

11. Hruška-Dell'Uomo, K. (1976.): O livadnoj vegetaciji Moslavine. Acta Bot. Croat. 35: 135-142.

12. Horvatić, S., Gaži, V., Trinajstić, I. (1967.-1968.): Prilog poznavanju vegetacije vlažnih livada sjeverne Dalmacije. Acta Bot. Croat. 26-27: 181190.

13. Hulina, N. (1991.): Segetalna i ruderalna flora u području Turopolja. Frag. Herbol. 20 (1-2): 5-9.

14. Hulina, N. (2007.): Flora i vegetacija Drežničkog polja. Agronomski glasnik 4: 255-276.

15. Kovačević, J., Šatović, F. (1968.): Prirodni travnjaci općine Sesvete kao resursi krme. Veterinaria 17/2: 223-229.

16. Marković-Gospodarić, Lj. (1965.): Prilog poznavanju ruderalne vegetacije kontinentalnih dijelova Hrvatske. Acta Bot. Croat. 24: 91-136. 
Dubravka Dujmović Purgar i sur.: Gospodarska važnost i rasprostranjenost bijele djeteline (Trifolium repens L.) na području Republike Hrvatske

17. Marković, Lj. (1984.): Ruderalna vegetacija Gorskog kotara, Acta Bot. Croat. 43: 257-272.

18. Marković, Lj. (1987.): Das Urtico-Aegopodietum in Nordwestkroatien. Acta Bot. Croat. 46: 73-79.

19. Milović, M. (2002.): The flora of Šibenik and its surroundings, Nat. Croat. 11 (2): 171-223.

20. Nikolić, T. (2020.): Flora Croatica Database. On-Line: (http://hirc.botanic.hr/fcd). Botanički zavod, Prirodoslovno-matematički fakultet, Sveučilište u Zagrebu.

21. Pahlow, M. (1989.): Velika knjiga ljekovitog bilja. Cankarjeva založba, Ljubljana.

22. Pandža, M. (1998.): Flora of the island of Murter (Central Adriatic). Acta Bot. Croat. 57: 99-122.

23. Regula-Bevilacqua, Lj. (1979.): Ruderalna i korovna vegetacija na području Strahinščice. Acta Bot. Croat. 38: 105-122.

24. Stančić, Z. (1994.): Prikaz i analiza flore okolice Konjšćine (Hrvatska). Acta Bot. Croat. 53: 125-140.

25. Šimić, F. (1980.): Naše medonosno bilje. Znanje, Zagreb.

26. Šoštarić - Pisačić, K. (1967.): Višegodišnje kulturne Trifolium vrste. Poljoprivredni fakultet, Zagreb.

27. Šoštarić - Pisačić, K., Kovačević, J. (1968.): Travnjačka flora i njena poljoprivredna vrijednost. Nakladni Zavod Znanje, Zagreb.

28. Topić, J. (1984.): Phytocenological and phytogeographical characteristics of the hoe weed vegetation in the continental part of Croatia. Acta Bot. Croat. 43: 273-284.

29. Topić, J. (1998.): Quantitative analysis of weed flora of Podravina region (North Croatia). Acta Bot. Croat. 57: 55-649th EWRS Symposium, Budapest: 155-160.

30. Trinajstić, I. (1980.): Prilog sintaksonomskom proučavanju vegetacije okopavinskih korova u Gorskom kotaru. Frag. Herbol. Jugosl. 9 (1): 1721.

31. Trinajstić, I. (1985.): Flora otočne skupine Korčule. Acta Bot. Croat. 44, 107-130.

32. Tucak, Z., Bačić, T., Horvat, S., Puškadija, Z. (1999.): Pčelarstvo. Poljoprivredni fakultet, Osijek. 
Dubravka Dujmović Purgar i sur.: Gospodarska važnost i rasprostranjenost bijele djeteline (Trifolium repens L.) na području Republike Hrvatske

33. Uher, D. (2002.): Najvažnije mahunarke naše travnjačke flore (II). Gospodarski list 24: 57.

34. Uher, D. (2005.): Bijela djetelina osobito pogodna za muzne krave. Gospodarski list 22: 57.

35. Vrbek, M. (2000.): Ruderalna i korovna flora Žumberka. Magistarski rad, Sveučilište u Zagrebu.

Prikazani rezultati proizašli su iz znanstvenog projekta (Genetska varijabilnost crvene djeteline i tolerantnost na abiotske stresove), provođenog uz potporu Ministarstva znanosti, obrazovanja i športa Republike Hrvatske.

Adresa autora - Author's addresses:

Izv. prof. dr. sc. Dubravka Dujmović Purgar

e-mail: dpurgar@agr.hr

Zavod za poljoprivrednu botaniku,

Prof. dr. sc. Snježana Bolarić

Zavod za oplemenjivanje bilja, genetiku, biometriku i eksperimentiranje, Agronomski fakultet Sveučilišta u Zagrebu,

Svetošimunska 25, 10000 Zagreb

Dubravka Koprivnjak

Trnovitička ulica 9a, 10040 Zagreb
Primljeno - Recived:

15.02.2020. 
Dubravka Dujmović Purgar i sur.: Gospodarska važnost i rasprostranjenost bijele djeteline (Trifolium repens L.) na području Republike Hrvatske 